\title{
3
}

\section{New Emerging Technologies for University Innovation}

\author{
David Blas Padilla \\ d.blas.at@gmail.com \\ Orcid: 0000-0002-5131-1066 \\ University of Pablo de Olavide \\ Julio Cabero Almenara \\ cabero@us.es \\ Orcid: 0000-0002-1133-6031 \\ University of Seville
}

\author{
Esteban VÁzouez Cano \\ evazquez@edu.uned.es \\ Orcid: 0000-0002-6694-7948 \\ National Distance Education \\ University \\ Eloy López Meneses \\ elopmen@upo.es \\ Orcid: 0000-0003-0741-5367 \\ University of Pablo de Olavide
}

\begin{abstract}
The present study has been carried out under the umbrella of a wider Spanish research project "Augmented Reality to enhance the development, design, production and evaluation of AR aided HE training programmes" (EdU-5746-PProyecto RAfodIUn). This immersive educational experience was conducted through a seminar about emergent technologies, the aims of which were 1) Raise awareness of new AR applications in educational settings, as well as their pedagogical potential applications, 2) generate proactive attitudes of students towards AR, and 3) develop students' competencies around the pedagogical applications of AR. The results show that, among a set of AR applications, Quiver and Zookazam were the most attractive and motivational for educational purposes, while other applications such as Anatomy 4D were not so suited for this purpose, despite being a highly powerful application in the field of healthcare.
\end{abstract}

Keywords: Technological education, augmented reality, educational apps, Higher Education innovation, emerging technologies 


\subsection{Augmented Reality: new technologies that generate proactive learning scenarios}

The present digital era is moving towards new ways of interacting with reality through "new" interactive and emerging technologies, bringing people closer to a culture of collaborative knowledge (Cope and Kalantzis, 2010), whose trend tend towards privacy, connected content, globality as a process, the use of mobile phones, a digital identity and b-learning, among others.

Nowadays, emerging technologies such as Augmented Reality (AR) are increasing their popularity in training scenarios (Kipper \& Rampolla, 2012, Moreno-Martínez and Leiva-Olivencia, 2017). In this sense, the "Augmented Reality" is a technology that allows the combination of digital information and physical information in real time, through different technological supports, such as tablets or smartphones, and that allows creating a new reality (Cabero y Barroso, 2016, Cabero et al. 2016, Fombona y Vázquez-Cano, 2017, Cabero y Barroso, 2018).

Its meaning for educational training is established, on the one hand, by its own specific features, such as: being a mixed reality, the chance to combine, in real time, different layers of information and in different formats (texts, url, videos, ...), it is an interactive technology, it is easy to use, and through its use we make richer or change the information of reality by adding additional information (Cabero and García, 2016). And on the other hand, because the devices that are often used for observation, such as smartphones, are technologies easily available to university students (Cabero y Barroso, 2018).

From a technological point of view, combining the proposals of different authors, Cabero and Barroso (2016) point out the different resources and technological devices that are needed for the production and observation of objects in $\mathrm{AR}$, in particular the authors point out the following:

1. An element that captures the image of reality that users are seeing (computer screen, a telephone, or a video game console);

2. A device where to project the mixture of the real images with the synthesized images (the three mentioned above can be used);

3. A processing element or several that work together whose function is to interpret the real world information that the user re- 
ceives, generate the virtual information that each specific service needs and mix it in an appropriate way (computers, mobiles or videoconsoles);

4. A specific type of software to produce the program;

5. An augmented reality activator or markers that can be QR codes, physical objects, GPS ...; and

6. A content server where the virtual information that we want to incorporate into reality is located.

Finally, despite the great possibilities offered by this technology, as Fernández-Robles (2018) points out, we have some challenges to incorporate it into the teaching-learning process and, among them, we can find the following: the lack of teacher training, the lack of resources and objects of learning of AR, not enough centres that support professors in the production of learning objects of AR, and a lack of experiences with AR that could be used as support (Billinghurst y Düenser, 2012; Cabero y García, 2016). In addition, the AR needs contextualized studies in educational processes that allow research into its advantages and limitations; a technology whose functionality and practicality has been highlighted by different researchers (Prendes, 2015; Garay et al., 2017).

\subsection{Scenario of the study}

The immersive innovative experience is developed through a Seminar on Emerging Technologies carried out in the months of January and February in the academic year 2017-18 in the subject: "Information and Communication Technologies in Social Education", linked to the first year of the Degree in Social Education of the Faculty of Social Sciences of the Pablo de Olavide University, of Seville (Spain) with a load of 7.3 ECTS Credits (European Credit Transfer System). With regard studies program, the subject of "Information and Communication Technologies in Social Education" belongs to the area of Didactics and Educative Organization and is organized around several thematic blocks; in our case, corresponds to the fourth content core called: "Social / cross-cutting themes", in particular it belongs to the unit 9: "Augmented Reality in social training scenarios". The conceptual scheme of the subject can be found at the following link: <http://bit.ly/2xwjh $4 \mathrm{x}>$. 
The immersive didactic experience was made through a Seminar of Emerging Technologies whose objective was the following educational intentions: 1) Knowing the new applications of AR in educational settings and their pedagogical possibilities in educational contexts. 2) Generating in the students, proactive attitudes towards the augmented technologies and 3) Develop in the student's competences of didactic use on AR applications presented in the training seminar.

The Seminar on Emerging Technologies was developed in three sessions of two hours where the students of both degrees (Double Degree in Social Work and Social Education) learned the concept of the AR, the levels of this technology, the possibilities and limitations of the AR in formative scenarios and the practical use of different applications of AR oriented to the socio-educational context, such as: Quiver, Zookazam, Chromville y Anatomy 4D. To do this, different tablets, paper printed markers (provided by the professor) and mobile phones of the students who downloaded the applications for the use of the AR were used. In Figure 1, students are shown using markers from the Zookazam app.
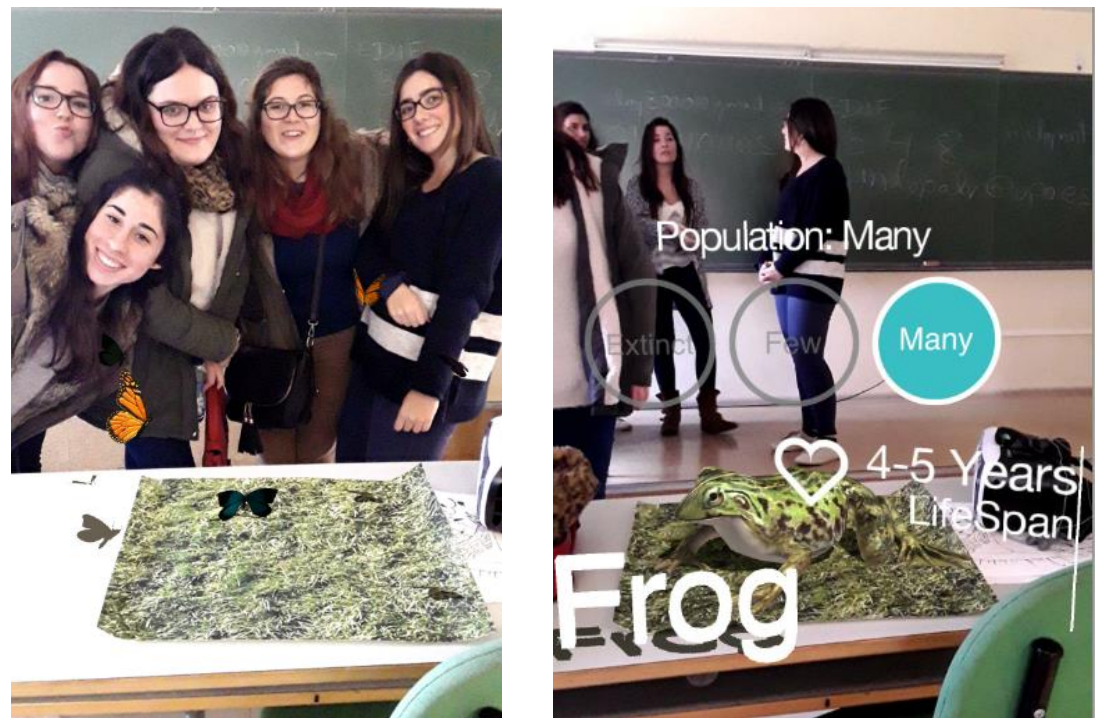

Figure 1. Students of the Pablo de Olavide University 2017-18 (Seville, Spain)

The training event aimed to achieve the following didactic intentions: 
- To know on the part of the students, educational apps of AR to use them in formative socio-educational scenarios.

- Encourage students to develop cognitive and metacognitive skills in the collaborative construction of object designs implemented with emerging technologies.

- Develop in the students, competences of didactic use of the AR apps used in the classroom.

In addition, in the edublog of the subject (Figure 2), a tab was designed called: "Augmented and Virtual Reality", which offered educational materials on this subject and presented a collection of other educational apps, tutorials and news of interest (<http:// cort.as/x-F4>).

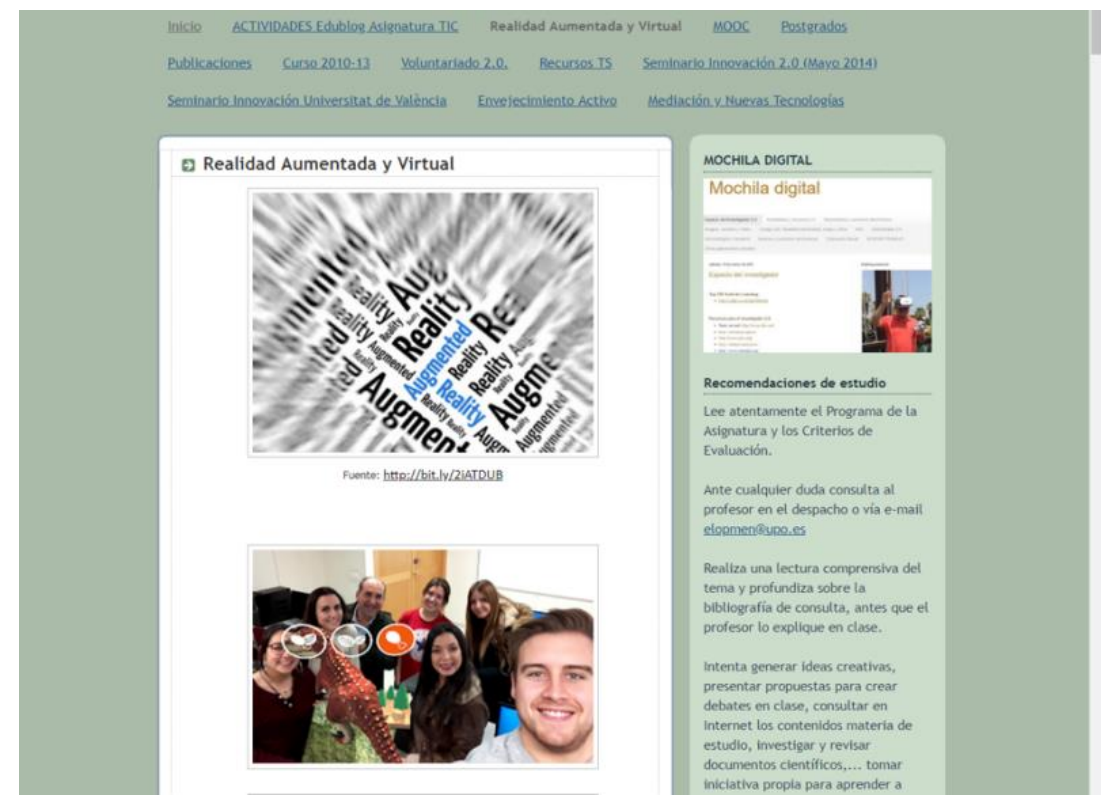

Figure 2. Edublog of the subject: "ICT and Social Education"

At the end of the training seminar each student was asked to complete a questionnaire prepared ad hoc entitled: "Didactic use of the AR", in order to investigate which application used in the AR training seminar was the most motivating, analyze the preferred areas of social intervention for using these immersive technologies 
and expose the advantages and limitations of AR in the educational context. Its link is: <https://goo.gl/forms/STik3sI9KdPzZi773>.

Ultimately, each student had to develop a personal edublog for the subject on the evidence of the activities carried out, where one of the tabs should be named Augmented Reality and there they should answer these three questions: 1) What is Augmented Reality (AR)? Advantages and Disadvantages of the AR in the training scenarios. 2) Make a brief comment (max 300 words) about the preferred areas of social intervention (Children, adults, elderly, community care ...) where this emerging technology (AR) can be applied and 3) What application of Augmented Reality seen in the Seminar on Emerging Technologies (Zookazam, Anatomy 4D, Quiver and Chromville) did you like more? In Figure 3, two examples of the edublogs that belong to the students of the Degree in Social Education of the academic year 2017-18 are displayed.

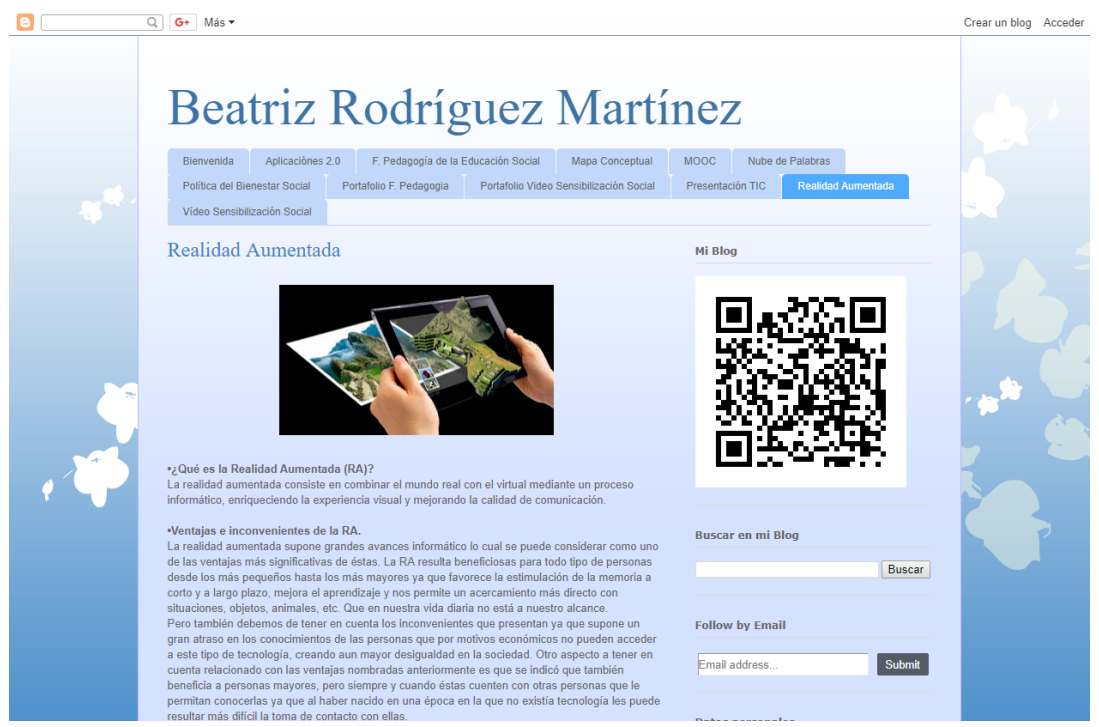

Figure 3. Edublog of a student of the Degree in Social Education. Academic year 2017/18. URL: <https://miblogdeticbeatrizrm.blogspot.com/p/realidad-aumentada.html>. 


\subsection{Methodological scenario}

We approach an exploratory study whose main objective is to know the most motivating and useful educational apps of AR used in the Seminar of immersive technologies for the academic year 2017-18 in the Degree in Social Education.

For this analytical study, the contributions made by the student group were checked by analyzing the words or sets of meanings as units of record. Subsequently, the guidelines established by different authors were taken as a frame of reference (Bogdan \& Biklen, 1992; Miles \& Huberman, 1994; Monje 2011). Specifically, in a first stage the data was reduced by categorizing and coding the information obtained. The categorization involved simplifying and selecting the information to make it more manageable. For this we follow the following steps:

- Separation of units to identify significant segments of information on the reflections formulated on the concept of Mediation.

- Identification and classification of the units in order to group them conceptually in groups that shared the same topic with meaning.

- Synthesis and grouping of the different information units.

During coding, each textual unit was related to its category through a mixed procedure (inductive-deductive) to proceed subsequently to its frequency count and percentages count.

Ultimately, all categorized information units were analyzed to facilitate the stage of inference and interpretation of results presented below.

The participating sample consisted of: 56 students of the first year of the Degree in Social Education (Subject: "ICT and Social Education") of the academic year 2017-18.

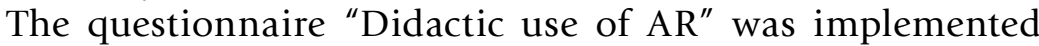
(link: <https://goo.gl/forms/STik3sI9KdPzZi773>). The questionnaire design was based on the theoretical considerations made by Barroso and Gallego-Pérez (2017) and was checked by expert judgment in two rounds by means of a Delphi study. The main objective of the questionnaire was to obtain the opinion of the students according to descriptive aspects, such as the preferred areas of intervention, its advantages and limitations and the perceptions 
about the different AR apps used in the aforementioned Seminar on Immersive Technologies. In our study we analyze the appreciations and impressions of the 56 students related to the AR apps used in the university classrooms. For this we rely on clicker-based technologies (audience response systems), that is, tools that can be applied in the educational context as feed-back with the student, very useful for monitoring student learning (Caldwell, 2007) and there is evidence that clickers have positive effects on cognitive learning (Hunsu, Adesope \& Bayly 2016).

\subsection{Results of the immersive innovative experience}

First, the response frequency of the 56 students on the most attractive and usable AR apps used in the subject's practices is compiled in Figure 4: "ICT and Social Education" in the Social Education Degree in the academic year 2017-18.

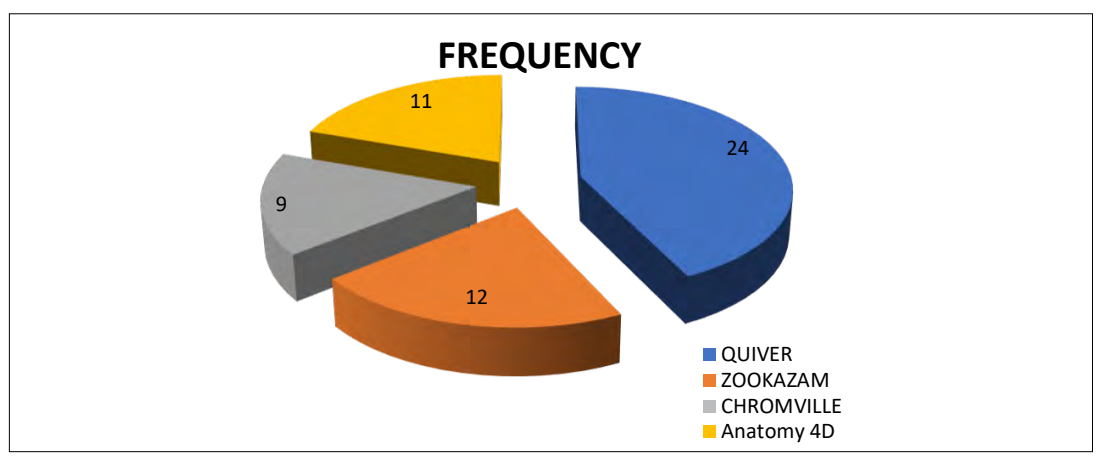

Figure 4. Frequencies of responses from the students of the Degree in Social Education, regarding the most motivating AR apps (2017-18).

Next, Figure 5 shows the perceptions of the 56 students about the AR apps used in the Seminar on Emerging Technologies corresponding to the Degree in Social Education in the academic year 2017-18.

As can be seen in the percentage analysis, the students of the Degree in Social Education (2017-18) reported that the most motivating AR apps used in the Seminar on Emerging Technologies were: Quiver with one (44\%), followed by the app Zookazam (23\%), Chromville (14\%) and the least interesting Anatomy 4D (19\%). 


\section{PERCENTAGE}

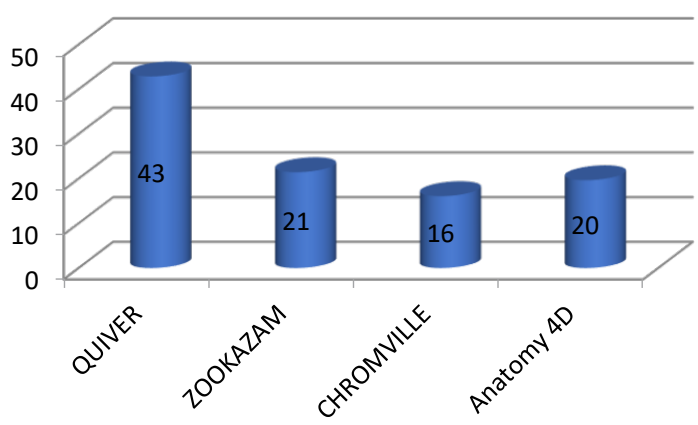

Figure 5. Percentage of the most significant AR apps of the Degree in Social Education for the 2017-18 academic year.

Finally, they showed that Quiver and Zookazam were the most attractive and motivating apps because they were very easy to use, usable, friendly and oriented to educational processes, while the other two were less usable and, in particular, Anatomy 4D was a very specialized and specific app for the field of health. But, all affirmed that these AR apps fostered cognitive abilities, spatial abilities and increased positive attitude and understanding in educational processes. In addition, they also reflected that these apps could offer friendly training scenarios for communication, the promotion of gamification in training scenarios and these could be very suitable and functional didactic resources for their professional future in social contexts.

\subsection{Final reflexions}

In the first place, it is found in agreement with other studies (Bressler \& Bodzin, 2013, Cozar et al., 2015, Cabero, Llorente, \& Gutiérrez-Castillo, 2017) that this type of emerging technologies show that students have favorable attitudes towards them and their use favors the motivation towards learning. Besides, it also stimulates a proactive teaching environment (Fombona et al., 2012) and favors a high level of student satisfaction (Han et al., 2015, Kim, Hwang, \& Zo, 2016). Likewise, as stated in another research 
(Cabero, Vázquez-Cano, \& López-Meneses, 2018), the use of AR has been useful in the construction of emerging competences on the use of ICT, the ability to work in teams, the discovery of new immersive didactic resources useful in the scenarios of Social Education and Social Work, unknown by the majority of students, which can help the development of new training processes from a constructivist and researching perspective. In this sense, we want to emphasize that the didactic activities based on the AR can be especially useful in pre-university and higher education studies related to the Humanities and Social Sciences areas, because these activities allow access to contents that are often presented in a more unidirectional way through printed paper that does not increase motivation or require a greater effort of abstraction among students. With this resource, the contents are visualized in a more creative, dynamic and real way, achieving a more attractive, innovative and motivating didactic at any educational level.

The analysis of the didactic experience of the application of the AR with university students allows us to assert as a first conclusion that the use of objects based on augmented technology in Higher Education, arouses real interest among students. This has also been corroborated by different studies that show high levels of satisfaction when students use this technology and the significant increase in levels of motivation when students are immersed in training actions with AR (Chin-Ming \& Yen Nung, 2011; Neven, Hala, \& Mohamed, 2011; Di Serio et al. 2013; Wojciechowski \& Cellary, 2013; Cózar et al. 2015; Kim, Hwang \& Zo, 2016;). In addition, the students have also commented at the Seminar on emerging technologies that its use is interesting and fun, in accordance with other studies (Teo \& Noyes, 2011; Fernández-Robles, 2018)

Despite this increase in motivation among students, the application of the AR must also overcome certain limitations such as the possible dehumanization of methodological processes and the need for a relative economic investment that may cause an increase in the digital divide in society and in education.

Despite these limitations, it should be noted in line with Barroso, Cabero \& Moreno-Fernández (2016), that their incorporation into teaching is easy, since almost all students have mobile devices and know how to download AR applications. On the other hand, as it is also extracted from the analysis of the results and confirming the study carried out by Barroso \& Gallego-Pérez (2017), it is 
interesting to see how, in their opinion, a technology like the AR can be used by themselves in their future professional development. In addition, the immersive innovating experience has been useful in the construction of emerging competences on ICT use, ability to work in teams, the discovery of new immersive didactic resources useful in the scenarios of Social Education and Social Work which were unknown by most of the students, which can help the development of new training processes from a constructivist perspective.

Likewise, as it was indicated in 2015 by Cabero, Ballesteros, \& López-Meneses, we must state that in view of the current technological, social and communicative framework, Universities should adapt training processes (as the vast majority of them do) attending, among other aspects, to the current characteristics and needs of the students, allowing the easy incorporation of flexible and open scenarios for training and learning that help transform traditional communication models (characterized by the passivity of students) by others in which they can actively participate in the construction of knowledge and where they are aware of their own training process in the acquisition of skills and abilities. We speak, in short, about a new drawing for the university institution, the University 2.0 (Cabero \& Marín, 2011).

Ultimately, in accordance with Fernández-Robles (2018), augmented reality can be presented as a technology with real usefulness for university education, since it allows working with active and constructivist methodologies, it offers the possibility to visualize the object from different perspectives, allows the easy acquisition of difficult-to-access knowledge, enables the presentation of simulated scenarios, and enriches the printed material.

\section{Acknowledgment}

This work is in the research project called "Augmented Reality to Increase the Training, Design, Production and Evaluation of Augmented Reality Programs for University Education" (RAFODIUN) (EDU2014-57446-P). Besides, we thank the students of the subjects of Information Technology and Communication in Social Education, for the support offered in the innovative experience. 


\section{References}

Billinghurst, M. \& Dünser, A. (2012). Augmented reality in the classroom, Computer, 45 (7), 56-63.

Bogdan, R. \& Biklen, S. K. (1992). Investigación cualitativa de la educación. Needham Heights, MA: Allyn and Bacon.

Bressler, D. M. \& Bodzin, A. M. (2013). A mixed methods assessment of students'flow experiences during a mobile augmented reality science game. Journal of Computer Assisted Learning, 29 (6), 505-517.

Cabero, J. \& Barroso, J. (2016). The educational possibilities of Augmented Reality, NAER. New Approaches in Educational Research, 5 (1), 44-50.

— (2018). Los escenarios tecnológicos en realidad aumentada (RA): posibilidades educativas en estudios universitarios, Aula Abierta, 47 (3), 327-336.

Cabero, J. \& García, F. (coords.). (2016). Realidad aumentada. Tecnología para la formación. Madrid: Síntesis.

Cabero, J., Leiva, J., Moreno, N., Barroso, J., \& López, E. (2016). Realidad aumentada y educación. Innovación en contextos formativos. Barcelona: Octaedro.

Cabero, J., M. C. Llorente, \& Gutiérrez-Castillo, J. (2017). Evaluación por y desde los usuarios: objetos de aprendizaje con realidad aumentada, RED. Revista de Educación a Distancia, 53, 1-17.

Cabero, J., Vázquez-Cano, E., \& López-Meneses, E. (2018). Uso de la realidad aumentada como recurso didáctico en la enseñanza universitaria, Formación Universitaria, 11 (1), 25-34.

Cope, B. \& Kalantzis, M. (2010). Ubiquitous Learning. Chicago: University of Illinois Press.

Cozar, R., De Moya, M., Hernández, J., \& Hernández, J. (2015). Tecnologías emergentes para la enseñanza de las Ciencias Sociales. Una experiencia con el uso de realidad aumentada en la formación inicial de maestros, Digital Education Review, 27, 138-153.

Fernández-Robles, B. (2018). La utilización de objetos de aprendizaje de realidad aumentada en la enseñanza universitaria de educación primaria, International Journal of Educational Research and Innovation (IJERI), 9, 90-104.

Fombona, J. \& Vázquez-Cano, E. (2017). Posibilidades de utilización de la geolocalización y realidad aumentada en el ámbito educativo, Educación XX1, 20 (2), 319-349.

Fombona, J., Pascual, M. J., \& Madeira, M. F. (2012). Realidad aumentada, una evolución de las aplicaciones de los dispositivos móviles, Píxel-Bit. Revista de Medios y Educación, 41, 197-210. 
Han, J., Jo, M., Hyun, E., \& So, H. (2015). Examining young children's perception toward augmented reality-infused dramatic play, Education Technology Research Development, 63, 455-474.

Kim. K., Hwang, J., \& Zo, H. (2016). Understanding users' continuance intention toward smartphone augmented reality applications, Information Development, 32 (2), 161-174.

Kipper, G. \& Rampolla, J. (2012). Augmented reality. Amsterdam: Syngress.

Miles, M. B. \& Huberman, A. (1994). Qualitative Data Analysis: An Expanded Sourcebook. Newbury Park, CA: Sage.

Monje, C.A. (2011). Metodología de la investigación cuantitativa y cualitativa. Guía didáctica. Nieva: Universidad Surcolombiana. Facultad de Ciencias Sociales y Humanas. Programa de Comunicación Social y Periodismo.

Moreno-Martínez, N., \& Leiva-Olivencia, J. J. (2017). Experiencias formativas de uso didáctico de la realidad aumentada con alumnado del Grado de Educación Primaria en la Universidad de Málaga, Revista de Educación Mediática y TIC (Edmetic), 6 (1), 81-104.

Teo, T. \& Noyes, J. (2011). An assessment of the influence of perceived enjoyment and attitude on the intention to use technology among pre-service teachers: A structural equation modeling approach, Computers \& Education, 57 (2), 1645-1653. 
